Background and aims Long term complications and mortality of Systemic Lupus Erythematosus Systemic(SLE) associated with vascular disease and atherosclerosis. Atherosclerosis is clinically preceded by changes in the walls of arteries, known as Intima Media Thickness (IMT) and plaque formation. IMT can be measured by B-mode ultrasonography of the carotid arteries. Atherosclerosis is an inflammatory process that was affected by inflammatory cytokines including TNF $\alpha$. The role of TNF- $\alpha$ is important in SLE disease, so it is important looking for correlation between plasma level of TNF $\alpha$ with carotid artery IMT from SLE patient.

Objective To determine the correlation between plasma level of TNF- $\alpha$ with carotid artery IMT from SLE patient.

Methods Cross Sectional Study, the subjects of this study was 32 people, consisting of woman aged $\geq 18$ years. Statistical test using unpaired t-test and Spearman rank correlation test.

Results From 32 subjects there were 20 subject (62,50\%) have a carotid artery IMT. There were no significant differences in plasma levels of TNF- $\alpha$ to carotid artery IMT( $p=0405$, 95\% CI -2.34 until 5,64), no significant correlation between plasma levels of TNF- $\alpha$ with carotid artery IMT $(p=0075$; $\mathrm{r}=-0,319)$ in SLE patient. We compare subject with carotid artery IMT which have high and low plasma levels of TNF $\alpha$ is same $(31,25 \%$ vs $31,25 \%)$

Conclusions There were no significant differences and no significant correlation between plasma levels of TNF $\alpha$ with carotid artery IMT in SLE patient

\section{EARLY RESULTS OF PATIENTS WITH ANTIPHOSPHOLIPID SYNDROME AND SYSTEMIC LUPUS ERYTHEMATOSUS FOLLOWING PULMONARY ENDARTERECTOMY}

${ }^{1} S$ Olgun Yildizeli, ${ }^{2} \mathrm{~N}$ Inanc* ${ }^{3} \mathrm{~B}$ Mutlu, ${ }^{2} \mathrm{Y}$ Sahinkaya, ${ }^{4} \mathrm{M}$ Yanartas, ${ }^{4} \mathrm{~S}$ Tas, ${ }^{2} \mathrm{H}$ Direskeneli, ${ }^{5} \mathrm{~B}$ Yildizeli. ${ }^{1}$ Marmara University - School of Medicine, Pulmonary Disease, Istanbul, Turkey; ${ }^{2}$ Marmara University - School of Medicine, Rheumatology, Istanbul, Turkey; ${ }^{3}$ Marmara University - School of Medicine, Cardiology, Istanbul, Turkey; ${ }^{4}$ Kosuyolu Heart and Vascular Surgery, Kosuyolu Heart and Vascular Surgery, Istanbul, Turkey; ${ }^{5}$ Marmara University School of Medicine, Thoracic Surgery, Istanbul, Turkey

\subsection{6/lupus-2017-000215.166}

Background and aims Pulmonary hypertension is one of the most debilitating and fatal complications of systemic lupus erythematosus (SLE) and antiphospholipid syndrome (APS). These patients are prone to chronic thromboembolic pulmonary hypertension (CTEPH), for which the treatment of choice is pulmonary endarterectomy (PEA). It is a complex surgical procedure with removal of obstructive thromboembolic material from the pulmonary arteries in order to reduce pulmonary vascular resistance, relieve pulmonary hypertension $(\mathrm{PH})$ and alleviate right ventricular dysfunction. Hereby, we share our clinical experience of PEA for CTEPH in SLE and APS patients.

Methods Data were collected prospectively for consecutive patients with APS and SLE who underwent PEA over a 5 year period [2011-2016]. Case selection was made by consensus of a team consist of a cardiologist, pulmonologist, rheumatologist and thoracic surgeon. All the operations were performed by the same surgical team.

Results We identified 22 patients (5 male, 17 female) with APS and SLE. Mean age was 35 (range $=7$ to 57). Median NYHA score was III (II to IV). Mean pulmonary artery pressure (mPAP) of the patients fell immediately from 77.4 $\pm 30.8 \mathrm{mmHg}$ to $28.8 \pm 8.9 \mathrm{mmHg}$ right after surgery, and
31.2 $\pm 7.5 \mathrm{mmHg}$ on discharge. One (5.9\%) patient developed acute respiratory distress syndrome and died on postoperative day 10. Mean follow-up duration was 31 months, with no additional mortality.

Conclusions Patients with SLE and/or APS should be screened for CTEPH, since they are more susceptible to intravascular thrombosis. PEA is the treatment of choice for CTEPH patients, with its low morbidity and high success rates.

\section{CLINICAL EVALUATION OF SYSTEMIC LUPUS ERYTHEMATOSUS PATIENTS FOR SKIN LESIONS-REPORT FROM A DEVELOPING COUNTRY}

${ }^{1} \mathrm{Z}$ Haider, ${ }^{2} \mathrm{MN}$ Islam, ${ }^{3}$ A Asaduzzaman, ${ }^{4} \mathrm{~N}$ Ferdous", ${ }^{5} \mathrm{JJH}$ Rasker. ${ }^{1} B S M M U$, Rheumatology, Dhaka, Bangladesh; ${ }^{2} B S M M U$ and MOACandRC, Rheumatology, Dhaka, Bangladesh; ${ }^{3} B S M M U$, Dermatology, Dhaka, Bangladesh; ${ }^{4} M O A C a n d R C$, Rheumatology, Dhaka, Bangladesh; ${ }^{5}$ University of Twente, Psychology- Health and Technology, Enschede, Netherlands Antilles

\subsection{6/lupus-2017-000215.167}

Background and aims SLE patients often suffer from both specific, non specific skin lesions and infections. This study was aimed to observe frequency of lupus specific and non-specific skin lesions, skin infections and factors related to infections.

Methods This observational study was conducted in SLE clinic of BSMMU, Bangladesh. A total 148 patients were enrolled and followed for 1 year. Patients were evaluated at baseline, special and final visits. Clinical definitions and dermatologist opinion were used for diagnosis of skin lesions. Patient's demographics, SLE lesions, infection as well as relevant laboratory tests were recorded. Multivariate analysis was done for risk factors. Ethical clearance was obtained from IRB of BSMMU. Results A total 131patients (126 women and 5 men) completed the study period; their mean age was $28.75 \pm 8.17$ years. Frequency of skin lesions and infections were $71.76 \%$ (94) and $26.7 \%$ (35) respectively. Specific lupus lesions were malar rash $75.44 \%$ followed by DLE, $15.78 \%$. Photosensitivity (72.6\%), non-scaring alopecia (67.9\%), mucosal ulcer (47.6\%), raynaud's phenomenon $(23.8 \%)$ and hyper-pigmentation $(23.8 \%)$ were notable non-specific skin lesions. Common skin infections were tineasis (42.85\%), herpes infections (34.26\%), paronychia (20\%) and scabies (17\%). High SLEDAI score, low complements, prednisolone $(>10 \mathrm{mg} / \mathrm{day})$ and use of immunosuppressive agents at present or in past were found risk factors for skin infections.

Conclusions Skin infections were high in this study. Tineasis, herpes infections, paronychia and scabies were common. Active disease, use of prednisolone $>10 \mathrm{mg} /$ day and immunosuppressive therapy were observed risk factors. Vaccinations and judicious use of drugs might reduce the rate of skin infection.

\section{AUTOANTIBODIES IN SLE WITH PULMONARY HYPERTENSION PROMOTE A MIGRATION OF PULMONARY ARTERY SMOOTH MUSCLE CELLS}

Y Kato* ${ }^{*}$ K Shibata, T Kubota. Tokyo Medical and Dental University, Microbiology and Immunology, Tokyo, Japan

\subsection{6/lupus-2017-000215.168}

Background and aims The process of pulmonary vascular remodelling in pulmonary arterial hypertension (PAH) in 